\title{
The Sydney Multicentre Study of Parkinson's disease: a report on the first 3 years
}

\author{
MARIESE A HELY,* JOHN G L MORRIS,* DAVID RAIL, $\dagger$ WAYNE G J REID, $\dagger$ \\ DUDLEY J O'SULLIVAN, $\ddagger$ PETER M WILLIAMSON,§ SANDRA GENGE,\| \\ GERALD A BROE**
}

\begin{abstract}
From the Neurology Unit, Westmead Hospital,* Lidcombe Hospital, $†$ St Vincent's Hospital $\ddagger$ Royal North Shore Hospital, $\$$ Sandoz Australia Pty Ltd,\| and Department of Medicine, University of Sydney, ${ }^{* *}$ Australia
\end{abstract}

SUMMARY One hundred and twenty nine de novo patients with idiopathic Parkinson's disease are being followed over a 5 year period in a double-blind multicentre study comparing low-dose bromocriptine ( $<30 \mathrm{mg} /$ day) with low-dose levodopa-carbidopa ( $<600 / 150 \mathrm{mg} /$ day). Sixty six patients have been randomised to bromocriptine and 63 patients to levodopa-carbidopa. Improvement has been greater in the levodopa-carbidopa group than in the bromocriptine group. Involuntary movements have so far only occurred in patients on levodopa-carbidopa, the incidence being much lower than is usually described with conventional doses. Mild, end-of-dose failure has occurred in both treatment groups; however, no patient has developed the "on-off" phenomenon. Low-dose levodopa-carbidopa appears to be a more effective anti-Parkinsonian treatment than lowdose bromocriptine but more prone to cause dyskinesia.

The value of levodopa in the long-term treatment of Parkinson's disease is limited by the emergence of dyskinesia and the "on-off" phenomenon. ${ }^{1-3}$ Attempts to reduce the incidence of these problems by giving levodopa in low dosage have met with limited success. ${ }^{45}$ Dyskinesia has rarely been observed and the "on-off" phenomenon has not been described in patients treated with bromocriptine alone. ${ }^{6-8}$ Nausea, postural hypotension and confusion limit the use of bromocriptine in up to $35 \%$ of patients using conventional doses. ${ }^{9-11}$ Several studies have shown that these side-effects can be minimised by giving bromocriptine in low dosage. ${ }^{7213}$

The aim of this study is to compare the efficacy and side-effects of low dose bromocriptine ( $<30 \mathrm{mg} /$ day) with low-dose levodopa-carbidopa $(<600 / 150 \mathrm{mg} /$ day) over a 5 year period in de novo patients. We report the results of the first 3 years of the study during which patients were recruited.

\section{Methods}

One hundred and forty nine patients with idiopathic Parkinson's disease were recruited over a 3 year period from neurologists and general practitioners in the Sydney area.

Address for reprint requests: Dr J G L Morris. Westmead Hospital, PO Box 119, Wentworthville, NSW 2145, Australia.

Received 7 June 1988 and in revised form 24 September 1988. Accepted 27 September 1988 neurologists and general practitioners in the Sydney area. Although the target population was de novo patients, 15 patients who had received levodopa for less than 3 months were accepted into the study. This medication was ceased one month prior to the patient entering the trial. Four Sydney hospitals are participating in the study. At each hospital clinic a participating neurologist confirmed the diagnosis of idiopathic Parkinson's disease and the need to commence treatment. Patients were then stratified according to age and previous treatment $(18$ patients had been taking anticholinergics, 11 patients levodopa-carbidopa alone and 4 patients anticholinergics and levodopa-carbidopa). They were then randomised to receive either bromocriptine or levodopacarbidopa. Informed consent was obtained.

Patients were given a placebo preparation for 1 month during which time two baseline assessments were made. They were then given either $1 \mathrm{mg} /$ day of bromocriptine or $20 / 5 \mathrm{mg} /$ day of levodopa-carbidopa in identical looking capsules. The dose was increased gradually at weekly, then monthly intervals until the patient reported a satisfactory response. If the patient was receiving anticholinergics or amantadine, these were continued unchanged during the trial. Only the hospital pharmacist knew which drug the patient was taking. The code was broken only if: (1) the response was unsatisfactory, (2) unacceptable side-effects occurred, (3) a greater than maximum trial dose was required, (4) one of the trial endpoints occurred. The main end-points listed in the trial protocol were dyskinesia and the "on-off" phenomenon. If the response was inadequate, wherever possible the original trial drug was continued and the dose increased above the "low-dose" maximum of $30 \mathrm{mg} /$ day of bromocriptine and $600 / 150 \mathrm{mg} /$ day of levodopa-carbidopa. Patients continue to 
be followed even if they are no longer on the therapy initially allocated.

The patients were seen monthly for about 6 months during which time the hospital neurologists titrated the dose (Phase I). Thereafter, the patients returned to their referring neurologists for the major part of their care but continue to be assessed in the hospital clinics at six monthly intervals for four and a half years (Phase II).

One neurologist attends all clinics in addition to the four hospital neurologists and examines all patients at baseline, end of titration phase and yearly thereafter. At regular intervals a comparison is made between the scores of this neurologist and the hospital neurologists, following simultaneous independent examinations of patients, with the aim of achieving uniformity between the four participating hospitals.

Signs of Parkinson's disease are recorded on a modified Columbia Scale, ${ }^{14}$ giving a maximum score of 102 . Disability is recorded on a 5 point modified North Western University Disability Scale ${ }^{15}$ and symptoms and side-effects in standard questionnaires. The severity of the disease is graded on the Hoehn and Yahr Scale. ${ }^{16}$ Once a year, fluctuations are assessed by means of a pegboard test and standardised walking test performed at hourly intervals throughout the day. A neuropsychological assessment is made at baseline and after 3 and 5 years.

For the purposes of this communication, the Columbia scores at 1 and 2 years have been compared with baseline scores. The results of patients in the double blind aspect of the study have been analysed by the study statistician, the participating neurologists remaining blind to the drug being administered to individual patients.

\section{Results}

\section{Exclusions}

Of the 149 patients referred into the study, 10 have been excluded because they had the following: cystic lesion of the basal ganglia on CT (1), essential tremor (2), undetermined congenital disorder (2), progressive supranuclear palsy (1), Shy-Drager syndrome (1), suspected striato-nigral degeneration (1), pinealoma and hydrocephalus (1), life-long non-progressive bradykinesia (1). Ten further patients failed to complete Phase I: four moved elsewhere, five were noncompliant and one died from myocardial infarction.

\section{Patient cohorts}

One hundred and twenty nine patients have completed the titration phase; 63 were randomised to levodopacarbidopa and 66 to bromocriptine. The characteristics of these patients are shown in table 1.

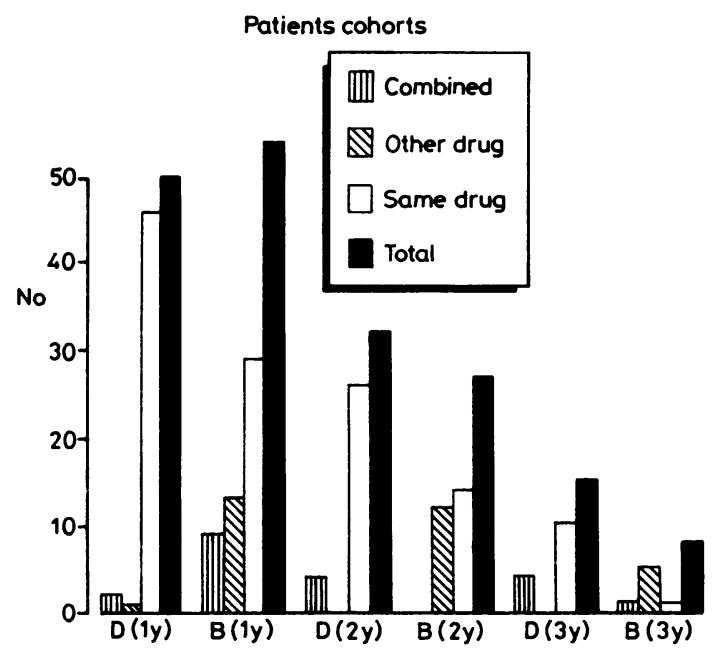

Fig $D(1 y)$ : levodopa-carbidopa group at 1 year; $B(1 y)$ : bromocriptine group at 1 year; Total: total number of patients originally allocated the drug; Same drug: number of patients still taking the drug originally allocated; Other drug: number of patients switched to the other drug being tested in this study; Combined: number of patients taking levodopacarbidopa and bromocriptine.

The figure shows the number of patients who have completed 1,2 and 3 years of treatment to date. It is clear that far fewer patients in the bromocriptine group remain on their original treatment as sole therapy than in the levodopa-carbidopa group.

\section{Doses}

The mean, daily doses of the two drugs in patients remaining on their initial therapy at 1,2 and 3 years are shown in table 2 . The daily dose for both drugs is rising progressively as the trial proceeds and it has been necessary to exceed the low-dose range in a small number of patients.

\section{Breaking the treatment code}

The reasons for breaking the drug code in the two groups of patients are shown in tables 3 and 4 . For bromocriptine, the major reason was lack of efficacy. In 12 patients the code was broken within 1 year. All but two of these patients had moderately severe disease (Hoehn and Yahr Stage III) and in some the disease was rapidly progressive. Of 10 patients in

Table 1 Characteristics of 129 patients completing phase I of trial

\begin{tabular}{|c|c|c|c|c|c|}
\hline Medication & $n$ & $\begin{array}{l}\text { Mean age } \\
\text { years (range) }\end{array}$ & $\begin{array}{l}\text { Mean duration of disease prior } \\
\text { to entry into trial months (range) }\end{array}$ & $\begin{array}{l}\text { Mean Hoehn \& } \\
\text { Yahr Stage (range) }\end{array}$ & $\begin{array}{l}\text { Mean Modified Columbia } \\
\text { score (range) }\end{array}$ \\
\hline $\begin{array}{l}\text { Levodopa-carbidopa } \\
\text { Bromocriptine }\end{array}$ & $\begin{array}{l}63 \\
66\end{array}$ & $\begin{array}{l}63 \cdot 0(41-79) \\
61 \cdot 8(42-76)\end{array}$ & $\begin{array}{l}24 \cdot 6(3-144) \\
21 \cdot 8(1-96)\end{array}$ & $\begin{array}{l}2 \cdot 2(1-3) \\
2 \cdot 3(1-3)\end{array}$ & $\begin{array}{l}15 \cdot 0(5-33) \\
18(3-33)\end{array}$ \\
\hline
\end{tabular}


Table 2 Doses of levodopa-carbidopa and bromocriptine at 1,2 and 3 years in patients remaining on original therapy

\begin{tabular}{|c|c|c|c|}
\hline & Mean dose (mg/day) & Range & $\begin{array}{l}\text { Patients exceeding } \\
\text { low dose maximum }\end{array}$ \\
\hline $\begin{array}{l}\text { One Year } \\
\text { Levodopa-carbidopa group }(n=46) \\
\text { Bromocriptine group }(n=29)\end{array}$ & $\begin{array}{l}335 / 83 \cdot 75 \\
18\end{array}$ & $\begin{array}{c}150-750 \\
5-45\end{array}$ & $\begin{array}{l}2 \\
1\end{array}$ \\
\hline $\begin{array}{l}\text { Two years } \\
\text { Levodopa-carbidopa group }(n=26) \\
\text { Bromocriptine group }(n=14)\end{array}$ & $\begin{array}{l}363 / 91 \\
22\end{array}$ & $\begin{array}{l}150-600 \\
6-35\end{array}$ & $\begin{array}{l}0 \\
1\end{array}$ \\
\hline $\begin{array}{l}\text { Three Years } \\
\text { Levodopa-carbidopa group }(n=10) \\
\text { Bromocriptine group }(n=1)\end{array}$ & $\begin{array}{l}380 / 45 \\
35\end{array}$ & $250-500$ & $\begin{array}{l}0 \\
1\end{array}$ \\
\hline
\end{tabular}

whom confusion occurred with bromocriptine, five had evidence of dementia at baseline.

Involuntary movements were the main reason for breaking the treatment code in patients receiving levodopa-carbidopa. Dyskinesia (choreo-athetoid movements often occurring at peak-dose times) began at a mean of 16 months (range 7-24 months) after commencing medication. The mean duration of disease prior to the onset of dyskinesia was 44 months (range 14-60 months). Nineteen percent of patients (six out of 32) had developed dyskinesia after 2 years on levodopa-carbidopa. Foot dystonia (sustained inversion of the foot, clawing of the toes or dorsiflexion of the large toe) appeared at a mean of 21 months (range 12-30 months) after treatment and after a mean duration of disease of $\mathbf{4 4}$ months (range 25-78 months). Sixteen percent of patients (five out of 32) had developed foot dystonia after 2 years.

Six patients on levodopa-carbidopa, three on bromocriptine and one on combined therapy have reported mild, end-of-dose deterioration. All three patients on bromocriptine had moderately severe disease, with Columbia scores of about 30 . In no case was the end-of-dose deterioration sufficiently severe to require an increased frequency of dosage of bromocriptine. Four of the six patients with this problem in the levodopa-carbidopa group are now taking the drug four or more times daily.

\section{Changes in the Columbia scores}

Changes in the Columbia scores at 1 and 2 years of all

Table 3 Reasons for breaking the drug code in patients randomised to bromocriptine

\begin{tabular}{lrl}
\hline Problem & No & $\begin{array}{l}\text { Mean dose (range) } \\
\text { mg/day }\end{array}$ \\
\hline Lack of efficacy $<30 \mathrm{mg} /$ day & 8 & $17(7 \cdot 5-25)$ \\
Lack of efficacy $>30 \mathrm{mg} /$ day & 14 & $42 \cdot 7(30-75)$ \\
Confusion & 10 & $13(1-30)$ \\
Postural hypotension & 3 & $13(10-15)$ \\
Nausea & 2 & $14(12 \cdot 5-15)$ \\
Lack of compliance & 2 & $11 \cdot 5(3-20)$ \\
Other & 1 & $17 \cdot 5$ \\
& 40 & \\
\hline
\end{tabular}

patients remaining on their initial therapy, regardless of whether the treatment code had been broken, are shown in tables 5 and 6. More patients improved and these to a greater degree on levodopa-carbidopa than on bromocriptine. At 1 year, $59 \%$ of patients on levodopa-carbidopa and $31 \%$ of patients on bromocriptine had a $20 \%$ reduction in the Columbia score. At 2 years, $58 \%$ of patients on levodopacarbidopa and $7 \%$ of patients on bromocriptine had improved by $20 \%$ or more. Patients who improved on low-dose bromocriptine tended to have mild disease with tremor. The number of patients who have been ino the trial for 3 years is not sufficient for a meaningfuB analysis.

Follow-up of patients no longer on initial therapy alone Twenty two patients did not improve on bromocriptine and had sufficient disability to warrant breaking the treatment code. Of these, 12 out of 13 improves when levodopa-carbidopa was added to the bromos criptine and six out of seven improved when bromocriptine was replaced by levodopa-carbidopa. Six out of 10 patients who became confused on bromocriptine also developed confusion on levodopacarbidopa.

Three patients, in whom levodopa has replaced bromocriptine, have developed dyskinesia after a mean of 15 months (range 4-31 months) on levodopa, while two other patients have developed dystonia of the foot after 2 and 12 months respectively on levodopa. The mean period of treatment with

Table 4 Reasons for breaking the drug code in Levodopacarbidopa group

\begin{tabular}{lcl}
\hline Problem & No & $\begin{array}{l}\text { Mean dose (range) } \\
\text { mg/day }\end{array}$ \\
\hline $\begin{array}{l}\text { Dyskinesia } \\
\text { Dystonia of foot }\end{array}$ & 7 & $386(300-500)$ \\
$\begin{array}{l}\text { Lack of efficacy } \\
<600 \mathrm{mg} / \text { day } \\
>600 \mathrm{mg} / \text { day }\end{array}$ & 7 & $357(250-550)$ \\
Confusion & 3 & $400(300-500)$ \\
& 1 & 750 \\
\hline
\end{tabular}


Table 5 Mean (\%) change in modified Columbia score for patients still on initial randomised therapy after one year

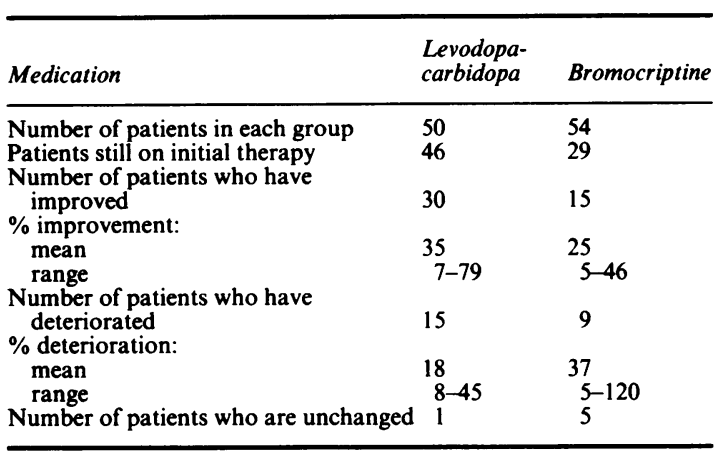

bromocriptine for these five patients was 16 months (range 5-33 months) prior to its cessation.

All four patients who had an inadequate response to low-dose levodopa responded to higher doses (mean $900 \mathrm{mg} /$ day).

\section{Discussion}

Differences in methods of assessment, duration of disease and previous treatment make it difficult to compare the results of this low-dose study with those of studies using conventional doses of levodopa. Comparisons with conventional doses of bromocriptine are rendered even more difficult by the fact that bromocriptine is used as an adjunct to levodopa in most studies. Nevertheless, there can be little doubt that fewer of our patients, both in the levodopacarbidopa and bromocriptine groups, have improved, and these to a lesser degree than patients treated with high doses of levodopa. After 2 years of treatment with conventional doses of levodopa, $63-77 \%$ of patients showed more than 20-25\% improvement in three large studies. ${ }^{17-19}$ By comparison, $58 \%$ of patients originally allocated levodopa-carbidopa and only $7 \%$ of patients originally allocated bromocriptine had

Table 6 Mean (\%) change in modified Columbia score for patients still on initial randomised therapy after two years

\begin{tabular}{|c|c|c|}
\hline Medication & $\begin{array}{l}\text { Levodopa- } \\
\text { carbidopa }\end{array}$ & Bromocriptine \\
\hline $\begin{array}{l}\text { Number of patients in each group } \\
\text { Patients still on initial therapy } \\
\text { Number of patients who have } \\
\text { improved } \\
\% \text { improvement: } \\
\text { mean } \\
\text { range } \\
\text { Number of patients who have } \\
\text { deteriorated } \\
\% \text { deterioration: } \\
\text { mean } \\
\text { range } \\
\text { Number of patients who are urchanged }\end{array}$ & $\begin{array}{l}32 \\
26 \\
18 \\
42 \\
6-60 \\
6 \\
27 \\
3-57 \\
2\end{array}$ & $\begin{array}{l}27 \\
14 \\
5 \\
16 \\
9-33 \\
8 \\
31 \\
8-89 \\
1\end{array}$ \\
\hline
\end{tabular}

Table 7 Incidence (\%) of abnormal involuntary movements (AIMS) in previous studies

\begin{tabular}{|c|c|c|c|}
\hline Authors & $\begin{array}{l}\text { Mean dose } \\
\text { of levodopa } \\
\text { (mg/day) }\end{array}$ & $\% A I M S$ & $\begin{array}{l}\text { Duration of } \\
\text { treatment } \\
\text { (years) }\end{array}$ \\
\hline $\begin{array}{l}\text { Lee, Sweet, McDowell } 1971^{18} \\
\text { Shaw, Lees, Stern } 1980^{19} \\
\text { Boshes } 1981^{24} \\
\text { Rascol } 1984^{25} \\
\text { Hoehn } 1985^{26} \\
\text { Lees, Stern } 1983^{27}\end{array}$ & $\begin{array}{l}\text { not stated } \\
950 \\
\text { review } \\
732 \cdot 9 \\
626 \cdot 8 \\
396\end{array}$ & $\begin{array}{l}85 \dagger \\
60^{*} \\
67^{*} \\
70 \dagger \\
36 \cdot 8^{*} \\
52 \cdot 9^{*} \\
33^{*}\end{array}$ & $\begin{array}{l}2 \\
1 \\
3 \\
2 \\
2 \cdot 5 \\
1-3 \\
3\end{array}$ \\
\hline
\end{tabular}

"peak dose dyskinesias only

†AIMS not specified

improved more than $20 \%$ at 2 years in this study. Moreover, the proportion of patients who had improved at 2 years was lower than at 1 year in the bromocriptine treatment group, suggesting a waning of therapeutic effect with time.

Lest it appear that we are condemning our patients to unnecessary hardship, it should be recalled that the aim of this study was to try to avoid the long-term problems associated with levodopa and bromocriptine therapy by giving the lowest dose which produced a satisfactory response. Our guiding principle was, therefore, to increase the dose of each drug until the patient reported a satisfactory response. This might involve an increase in independence or a return to previously abandoned activities and not be reflected in the Columbia score. Being a de novo study, many of our patients have mild disease (Hoehn and Yahr stage I and II), and a failure to show objective improvement in clinical signs at this stage is of little importance. Patients remaining in the double blind aspect of the study are all satisfied with their progress to date. This is the case after 2 years in 26 out of 32 patients in the levodopa-carbidopa group and in 14 out of 27 patients in the bromocriptine group.

Most published studies include patients with moderate or severe disability. In such patients the main aim of treatment is to produce maximal improvement. A similar approach was followed in 26 patients in this study who did not improve on the lowdose regimen and who had moderately severe or rapidly progressive disease (Hoehn and Yahr stage III and IV). In these patients the low-dose therapy was abandoned and conventional doses of levodopa-carbidopa and bromocriptine were given either singly or in combination.

This study confirms the findings of Poewe, Lees and Stern $^{20}$ that giving levodopa at low dosage does not prevent some patients from getting involuntary movements. The incidence, however, is considerably lower than with conventional doses (see table 7). None of our patients on bromocriptine has so far developed this side-effect, though five patients who were origin- 
ally allocated bromocriptine have since developed involuntary movements on levodopa-carbidopa. These results confirm the view that levodopa has a greater propensity to cause involuntary movements than bromocriptine. The reason for this remains unclear. One possibility is that involuntary movements result from stimulation of both D1 and D2 receptors. Bromocriptine is an agonist only for the latter. ${ }^{21}$ Denervation hypersensitivity, with failure of re-uptake of dopamine by degenerating pre-synaptic neurons, is also regarded as a possible mechanism of dopa-induced involuntary movements. ${ }^{19223}$ Our results show that levodopa is a more effective antiParkinsonian agent than bromocriptine but is more prone to produce involuntary movements. This suggests that the beneficial and, as far as involuntary movements are concerned, deleterious effects may be linked.

In conclusion, low dose levodopa-carbidopa appears to be a more effective anti-Parkinsonian treatment than low-dose bromocriptine. Although involuntary movements do occur with low dose levodopa-carbidopa, their incidence is much reduced compared with conventional doses. While no patient on bromocriptine has developed involuntary movements, measurable improvement has occurred in only a minority of patients. It is hoped, however, that this approach will reduce the incidence of long-term side-effects.

We acknowledge the roles of Dr Paul Teychenne in initiating this study and of Mrs Beverly Zielinsky in organising the clinics. Nick Moss helped to analyse the data. We thank Sandoz Ltd (Basle) for funding the study.

\section{References}

1 Muenter MO, Sharples NS, Tyce GM, Darley FL. Patterns of dystonia ("I-D-I" and "D-I-D") in response to L-dopa therapy for Parkinson's disease. Mayo Clin Proc 1977;52:163-74.

2 Melamud E. Early morning dystonia: a late side effect of long-term levodopa therapy in Parkinson's disease. Arch Neurol 1979;36:308-10.

3 Marsden CD, Parkes JD. "On-off" effects in patients with Parkinson's disease on chronic levodopa therapy. Lancet 1986;i:292-6.

4 Lees AJ, Stern GM. Sustained low dose levodopa therapy in Parkinson's disease: a 3 year follow-up. Adv Neurol 1983;37: 9-15.

5 Rajput AH, Stern W, Laverty WH. Chronic low-dose therapy in Parkinson's disease: an argument for delaying levodopa therapy. Neurology 1984;34:991-6.

6 Stern GM, Lees AJ. Sustained bromocriptine therapy in $\mathbf{5 0}$ previously untreated patients with Parkinson's disease. $A d v$ Neurol 1983;37:17-21.

7 Staal-Schreimemachers AL, Wesseling H, Kamphuis DJ, vd Burg W, Lakke JPWF. Low-dose bromocriptine therapy in Parkinson's disease: double-blind, placebo controlled study. Neurology 1986;36:291-3.

8 Grimes JD, Delgado MR. Bromocriptine: problems with low-dose de novo therapy in Parkinson's disease. Clin Neuropharm 1985;8(1):73-7.

9 Parkes JD. Bromocriptine in the treatment of Parkinsonism. Drugs 1979;17:365-82.

10 Parkes JD, Marsden CD, Donaldson I, Galea-DeBono A, Walker S, Kennedy G, Asselman I. Bromocriptine treatment in Parkinson's disease. J Neurol Neurosurg Psychiatry 1976;39: 184-93.

11 Fahn S, Cote LJ, Snider SR, Barrett RE, Isgreen WP. The role of bromocriptine in the treatment of Parkinsonism. Neurology 1979;29:1077-83.

12 Teychenne PF, Bergsrud D, Racy A, Elton RL, Vern B. Bromocriptine: low dose therapy in Parkinson's disease. Neurology 1982;32:577-83.

13 Pfeiffer RF, Wilken K, Glaeske C, Lorenzo AS. Low dose bromocriptine therapy in Parkinson's disease. Arch Neurol 1985;42:586-8.

14 Duvoisin RC. The evaluation of extrapyramidal disease. In: de Ajuriaguerra $\mathrm{J}$ ed, Monoamines noyaux gris centraux et Syndrome de Parkinson. Paris: Masson, 1970;313-25.

15 Canter GJ, de la Torre R, Mier M. A method for evaluating disability in patients with Parkinson's disease. J Neurol Ment Dis 1961;133:143-7.

16 Hoehn MM, Yahr MD. Parkinsonism: onset, progression and mortality. Neurology 1967;17:952-60.

17 Barbeau A. Six years of high level levodopa therapy in severely akinetic Parkinsonian patients. Arch Neurol 1976;33:333-8.

18 Lee JE, Sweet RD, McDowell FH. Treatment of Parkinsonism with levodopa. Follow-up after 2 years treatment. Ann Int Med 1971;75:703-8.

19 Shaw KM, Lees AJ, Stern GM. The impact of treatment with levodopa in Parkinson's disease. $Q J$ Med 1980;195:283-93.

20 Poewe WH, Lees AJ, Stern GM. Low dose L-dopa therapy in Parkinson's disease: a 6 year follow-up study. Neurology 1986;36:1528-30.

21 Markstein R. Neurochemical effects of some ergot derivatives: a basis for their antiparkinsonian actions. $J$ Neurol Trans 1981;51:39-59.

22 Yahr MD. Limitations of long-term use of antiparkinson drugs. Can J Neurol Sci 1984;11(1, Suppl):191-4.

23 Hornykiewicz $O$. Compensatory biochemical changes at the striatal dopamine synapse in Parkinson's disease-limitations of L-dopa therapy. In: Poirier LJ, Sourkes TL, Bedard PJ, eds. Extrapyramidal system and its disorders. Adv in Neurol Vol 24; New York, Raven Press 1979:275-81.

24 Boshes B. Sinemet and the treatment of parkinsonism. Ann Intern Med 1981;94:364-70.

25 Rascol A, Montastruc JL, Rascol O. Should dopamine agonists be given early or late in the treatment of Parkinson's disease? Can J Neurol Sci 1984;11, 1 (Suppl):229-32.

26 Maier Hoehn MM. Result of chronic levodopa therapy and its modification by bromocriptine in Parkinson's disease. Acta Neurol Scand 1985;71:97-106

27 Lees AJ, Stern GM. Sustained low-dose levodopa therapy in Parkinson's disease: a 3 year follow up. In: Fahn S, Calne DB eds. Experimental therapeutics of movement disorders. Adv in Neurol Vol 37, 1983:9-15. New York, Raven Press. 